\title{
Interference of hemolysis on the postmortem biochemical analysis of IgE by ECLIA
}

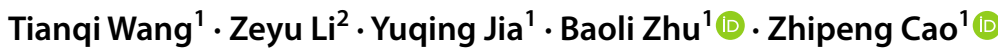

Received: 18 September 2020 / Accepted: 16 March 2021 / Published online: 30 March 2021

(c) The Author(s), under exclusive licence to Springer-Verlag GmbH Germany, part of Springer Nature 2021

\begin{abstract}
Forensic diagnosis of anaphylactic shock is a challenging task in forensic practice due to the lack of characteristic morphological changes. Postmortem analysis of serum IgE can provide helpful information for determining anaphylaxis. However, postmortem serum always suffers from hemolysis. To investigate the interference of hemolysis on postmortem analysis of total IgE by electrochemiluminescent immunoassay (ECLIA) and verify the suitability of the commercially available ECLIA kit for postmortem hemolyzed blood with the dilution-correction method, different levels of hemolyzed serum were prepared to evaluate the interference of hemolysis. A linear regression analysis was then performed on the concentration of total $\operatorname{IgE}$ in the completely hemolyzed blood and the corresponding serum. Our results indicated that hemolysis negatively interfered with the total IgE analysis by ECLIA and the interference (|Bias\%l) increased with increasing levels of hemolysis. After controlling for $\mid \mathrm{Bias} \% \mathrm{l}$ by dilution, the test concentration of total IgE in the completely hemolyzed blood was still significantly lower than that in the serum $(P<0.05)$ and resulted in eight false-negative cases. A strong correlation was observed between the test concentration of total IgE in the completely hemolyzed blood and that in the serum $(r=0.983)$. After correction by the regression formula, the corrected concentration revealed no significant differences and exhibited the same diagnostic ability, compared with the serum total IgE concentration. These results indicate that the completely hemolyzed blood is not recommended for postmortem analysis of total IgE directly. The dilution-correction method might have potential utility in forensic practice for evaluating serum total IgE concentrations.
\end{abstract}

Keywords Forensic medicine $\cdot$ Hemolysis $\cdot$ Postmortem biochemistry $\cdot$ Postmortem serum $\cdot \operatorname{IgE} \cdot$ Electrochemiluminescent immunoassay

\section{Introduction}

Anaphylactic shock is a rapid and fatal multisystem syndrome, and its forensic diagnosis is a challenging task for forensic pathologists in practical work due to the lack of characteristic morphological changes [1-3]. Previous reports have indicated that serum biomarkers, such as specific and total immunoglobulin E (IgE), tryptase, chymase, and histamine, are useful for postmortem diagnosis of anaphylaxis

Zhipeng Cao

zpcao@cmu.edu.cn

1 Department of Forensic Pathology, School of Forensic Medicine, China Medical University, No. 77, Puhe Road, Shenyang North New Area, Shenyang 110122, Liaoning Province, People's Republic of China

2 The Second Division of Clinical Medicine, China Medical University, Shenyang 110122, People's Republic of China
[4-10]. As a key mediator of classic IgE-mediated anaphylaxis, IgE is often used as one of the indicators for the diagnosis of anaphylactic diseases in both clinical and forensic medicine [11]. Clinical studies have demonstrated that hemolysis interferes with the measurement of multiple indicators and that hemolyzed samples are not suitable for biochemical analysis in clinical laboratories [12-15]. However, in forensic practice, blood samples always suffer from irreversible hemolysis due to postmortem changes, even within a short postmortem interval (PMI) [16], which induces unavailable or unsuitable serum for postmortem biochemical analysis of IgE. As a result, it is necessary to investigate the interference of hemolysis on the postmortem analysis of serum IgE, and effective methods of reducing the interference in hemolyzed blood samples should be identified.

The commercial electrochemiluminescent immunoassay (ECLIA) kit has been applied as a clinical measurement method for the biochemical analysis of $\operatorname{IgE}[17,18]$. 
Compared with the traditional enzyme-linked immunosorbent assay (ELISA) method, ECLIA has lower background noise and detection limits for analytes [14]. Clinical studies have shown that ECLIA exhibits good anti-interference ability against hemolysis in the measurement of various indicators and drugs, including the current new coronavirus pneumonia virus (COVID-19) antibody test [19-23]. However, no forensic reports are available on the postmortem analysis of IgE in hemolyzed samples with ECLIA.

Therefore, the present study first aims to investigate the interference of hemolysis on the analysis of total $\operatorname{IgE}$ with ECLIA by using different levels of hemolyzed serum, and subsequently further verify the suitability of the commercially available ECLIA kit for the postmortem hemolyzed blood samples with the dilution-correction method.

\section{Materials and methods}

\section{Sample collection}

Forty-nine autopsy cases (30 males and 19 females) with a mean age of 46.8 years (range 19-92 years) in the School of Forensic Medicine, China Medical University from 2017 to 2019 were included. The causes of death, which were diagnosed by three blinded forensic pathologists, included hemorrhage shock, hanging, mechanical asphyxia, traumatic shock, poisoning (alcohol and carbon monoxide), pneumonia, and cardiovascular and cerebrovascular accidents. No individuals died from anaphylactic shock. Comprehensive medico-legal autopsies were undertaken for each case within a PMI of $48 \mathrm{~h}$, and nonhemolyzed blood samples were collected from the left ventricle via incision at the aortic root using a Pasteur pipette. For each of the 49 included cases, the serum sample was obtained from $1 \mathrm{ml}$ of nonhemolyzed blood following centrifugation at $3000 \mathrm{~g}$ for $20 \mathrm{~min}$, and another $2 \mathrm{ml}$ of the nonhemolyzed blood was frozen at $-20{ }^{\circ} \mathrm{C}$ and slowly thawed at room temperature (approximately $24{ }^{\circ} \mathrm{C}$ ) for five cycles to prepare the completely hemolyzed blood sample. The serum and completely hemolyzed blood samples were stored at $-80{ }^{\circ} \mathrm{C}$ for biochemical analysis of total IgE. For six of the 49 included cases, $20 \mathrm{ml}$ of nonhemolyzed blood from each case was collected to prepare the concentrated hemolyzed blood for use in the different levels of hemolyzed serum samples according to the previous methods [24]. The flow diagram of the study design is shown in Fig. 1.

\section{Preparation of concentrated hemolyzed blood samples}

Twenty milliliters of the nonhemolyzed blood from each of six cases was centrifuged at $3000 \mathrm{~g}$ for $10 \mathrm{~min}$. All the upper serum was collected as the serum for total $\operatorname{IgE}$ analysis and preparation for different levels of hemolyzed serum samples. The lower blood cells were mixed with normal saline solution to a total volume of $50 \mathrm{ml}$, and then, the mixture was centrifuged at $3000 \mathrm{~g}$ for $10 \mathrm{~min}$. The lower blood cells were collected, and the supernatant was discarded. After five cycles of mixing-centrifuging-discarding, the total IgE concentration in the final discarded supernatant could not be measured by ECLIA $(<0.1 \mathrm{IU} / \mathrm{mL})$. The blood cells collected in the last round (approximately $10 \mathrm{ml}$ ) were vortexed and hemolyzed artificially by ultrasonication (500 Watts, $20 \mathrm{kHz}, 5 \mathrm{~min}$ ), and the concentrated hemolyzed blood sample was successfully prepared (Fig. 2). The concentrations of hemoglobin in these six concentrated hemolyzed blood samples were determined.

\section{Preparation of different levels of hemolyzed serum samples}

Hemoglobin concentration was employed to evaluate the degree of hemolysis. A total volume of $200 \mu \mathrm{l}$ mixture composed of different ratios of concentrated hemolyzed blood and the corresponding serum was prepared, which contained seven hemolyzed levels with hemoglobin concentrations from 10 to $200 \mathrm{~g} / \mathrm{L}$. The volume of the concentrated hemolyzed blood in the mixture is shown in Table 1 . The total IgE concentrations were determined in different levels of hemolyzed serum samples.

\section{Biochemical analysis}

The total IgE concentration was determined with a commercial ECLIA kit (electrochemiluminescent method, Roche Diagnostic GmbH, Mannheim Germany) using a Roche automatic electrochemiluminescent immunoassay analyzer (Cobas e411, Roche Diagnostic GmbH, Mannheim Germany). The hemoglobin concentration was analyzed with Van Kampen-Zijlstra's reagent (cyanmethemoglobin method, Zhongshan Institution of Tianjin Modern High-Tech Research Institute, Tianjin China) using a UV spectrophotometer (UV-1800, Shimadzu Corporation, Kyoto, Japan).

\section{Statistical analysis}

With reference to the previous study, Bias\% was used as an indicator to assess the interference of hemolysis on the analysis of total IgE by ECLIA. The formula for Bias\% is as follows:

$$
\begin{gathered}
C_{\text {calculation }}=C_{\text {serum }} \times \frac{V_{\text {serum }}}{200} I U / m l \\
\text { Bias\% }=\frac{C_{\text {test }}-C_{\text {calculation }}}{C_{\text {calculation }}} \times 100 \%
\end{gathered}
$$

where $C_{\text {serum }}$ represents the concentration of total $\operatorname{IgE}$ in the corresponding serum, which was subsequently added to the 
Fig. 1 Flow diagram of the study design

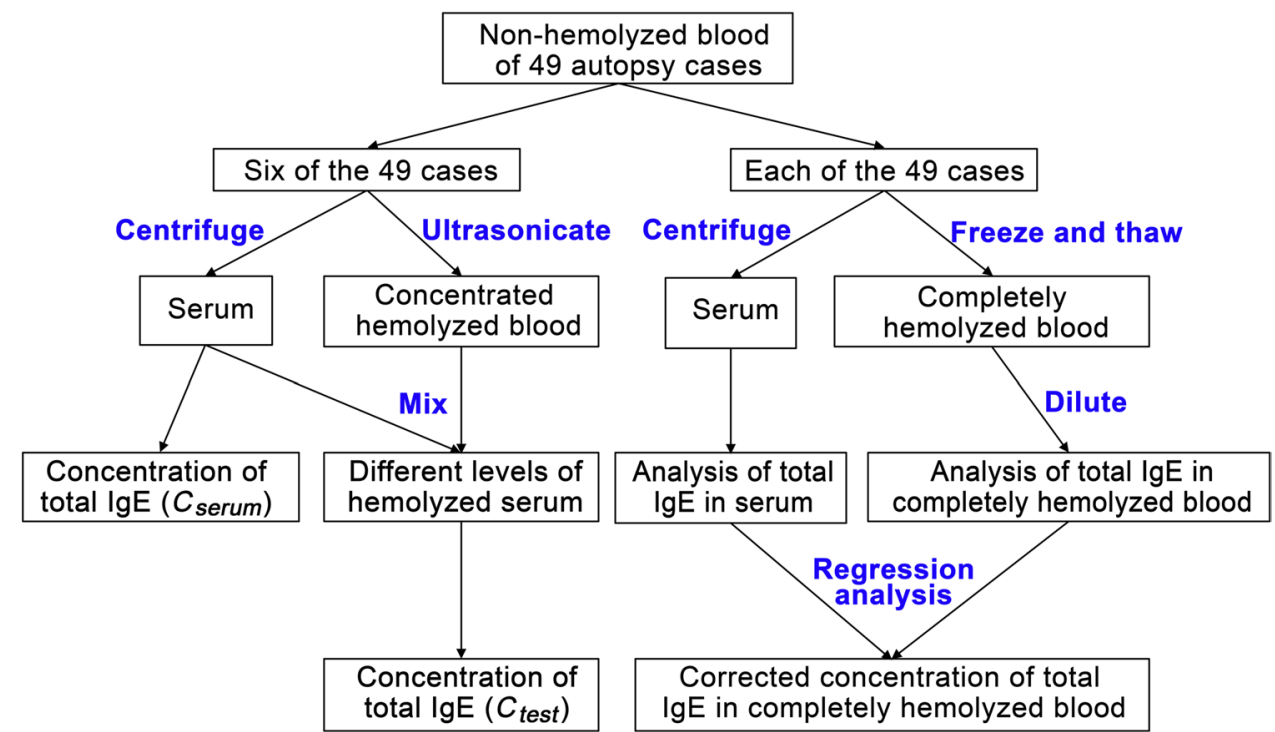

mixture of different levels of hemolyzed serum samples; $V_{\text {serum }}$ represents the volume of the added serum, which can be calculated with the data presented in Table 1; and $C_{\text {test }}$ represents the test concentration of total $\operatorname{IgE}$ in samples with different levels of hemolyzed serum [24, 25].

A linear regression analysis was conducted to analyze the correlation between the test concentrations of total $\operatorname{IgE}$ in the completely hemolyzed blood and that in the corresponding serum. The Wilcoxon signed-rank test was used to evaluate the difference in total IgE concentration among the paired samples. SPSS 20.0 (SPSS Inc., Chicago, IL) was used to perform the statistical analysis, and $P<0.05$ was considered statistically significant.

\section{Results}

\section{Interference of hemolysis on the analysis of total IgE by ECLIA}

To evaluate the interference of hemolysis on the biochemical analysis of total IgE by ECLIA, gradient hemolyzed serum samples were prepared. The color of the different levels of hemolyzed serum gradually became redder and darker as the hemoglobin concentration increased, and the transparency gradually decreased. The test concentration of total IgE in the mixture $\left(C_{\text {test }}\right)$ was lower than the corresponding calculation concentration $\left(C_{\text {calculation }}\right)$, and IBias $\%$ increased
Fig. 2 Preparation of concentrated hemolyzed blood and different levels of hemolyzed serum samples. $\mathrm{NS}=$ normal saline

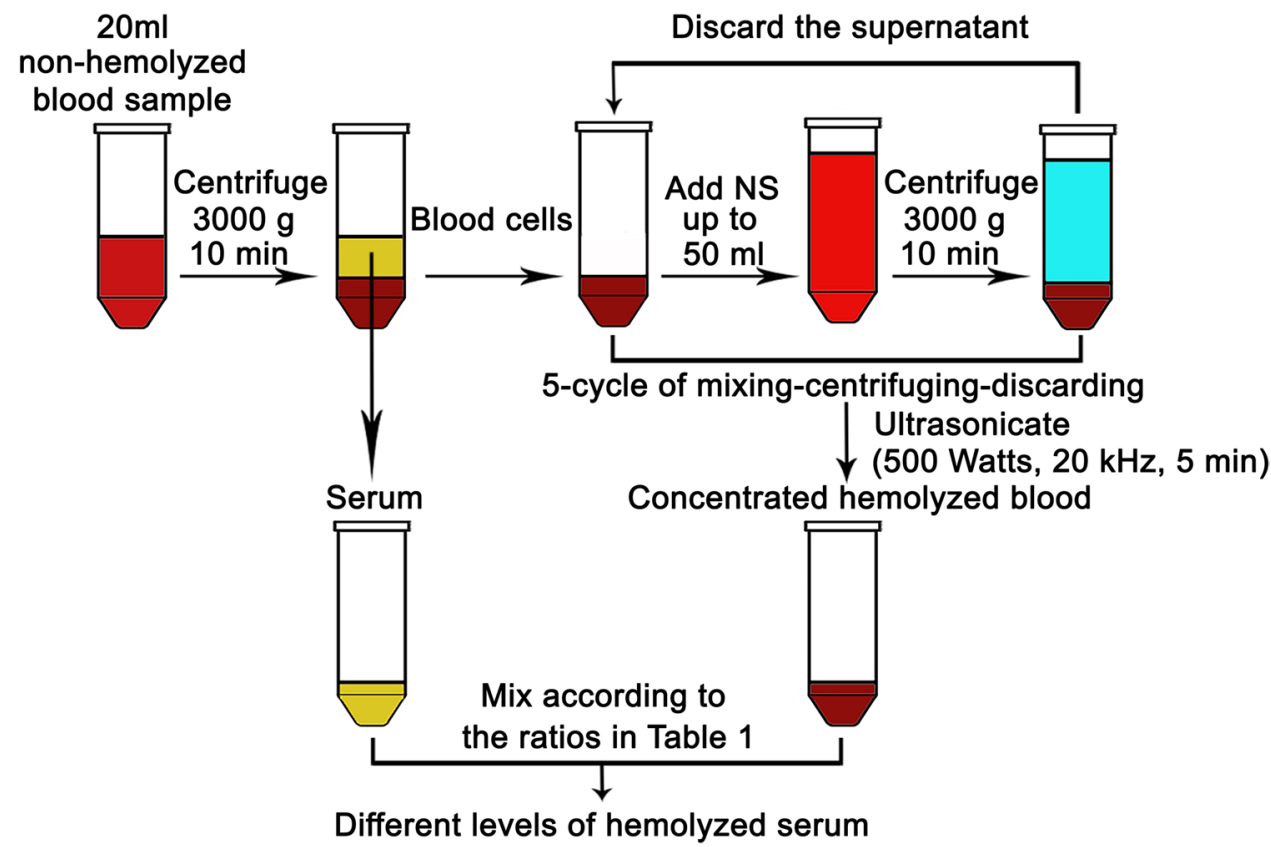


Table 1 Volume of concentrated hemolyzed blood in the mixture (ul)

\begin{tabular}{|c|c|c|c|c|c|c|c|}
\hline $\begin{array}{l}\text { Different levels } \\
\text { of hemoglobin } \\
(\mathrm{g} / \mathrm{L})\end{array}$ & $\begin{array}{l}\text { Case } 1 \\
\text { (hemoglobin: } \\
239.64 \mathrm{~g} / \mathrm{L} \text { ) }\end{array}$ & $\begin{array}{l}\text { Case } 2 \\
\text { (hemoglobin: } \\
204.87 \mathrm{~g} / \mathrm{L} \text { ) }\end{array}$ & $\begin{array}{l}\text { Case } 3 \\
\text { (hemoglobin: } \\
222.2 \mathrm{~g} / \mathrm{L} \text { ) }\end{array}$ & $\begin{array}{l}\text { Case } 4 \\
\text { (hemoglobin: } \\
252.87 \mathrm{~g} / \mathrm{L} \text { ) }\end{array}$ & $\begin{array}{l}\text { Case } 5 \\
\text { (hemoglobin: } \\
215.62 \mathrm{~g} / \mathrm{L} \text { ) }\end{array}$ & $\begin{array}{l}\text { Case } 6 \\
\text { (hemoglobin: } \\
232.90 \mathrm{~g} / \mathrm{L} \text { ) }\end{array}$ & Total volume \\
\hline 10 & 8.3 & 9.8 & 9.0 & 7.9 & 9.3 & 8.6 & \multirow{7}{*}{$\begin{array}{l}\text { Mixed with the } \\
\text { correspond- } \\
\text { ing serum } \\
\left(V_{\text {serum }}\right) \text { up to } \\
\text { a total volume } \\
\text { of } 200 \mathrm{ul}\end{array}$} \\
\hline 20 & 16.7 & 19.5 & 18.0 & 15.8 & 18.6 & 17.2 & \\
\hline 50 & 41.7 & 48.8 & 45.0 & 39.5 & 46.4 & 42.9 & \\
\hline 100 & 83.5 & 97.6 & 90.0 & 79.0 & 92.8 & 85.9 & \\
\hline 120 & 100.2 & 117.1 & 108.0 & 94.9 & 111.3 & 103.0 & \\
\hline 150 & 125.2 & 146.4 & 135.0 & 118.6 & 139.1 & 128.8 & \\
\hline 200 & 166.9 & 195.2 & 180.0 & 158.2 & 185.5 & 171.7 & \\
\hline
\end{tabular}

with each increase in the level of hemolysis. These observations indicate that hemolysis negatively interfered with the analysis of total IgE by ECLIA and that the more severe hemolysis corresponded to the greater interference (Fig. 3). The test concentrations $\left(C_{\text {test }}\right)$, calculation concentrations $\left(C_{\text {calculation }}\right)$, and Bias\% values are shown in Table 2.

\section{Linear regression analysis of total $\lg \mathrm{E}$ concentrations in the completely hemolyzed blood and serum}

Given the fact that hemolysis negatively interfered with the analysis of total IgE performed with a commercially available ECLIA kit, we further investigated whether dilution of the completely hemolyzed blood can be used to estimate the level of total $\operatorname{IgE}$ in the serum. Due to the lack of quality control standards for postmortem biochemical analysis, a $\mid$ Bias\%| value within $10 \%$ was considered acceptable, according to previous relevant clinical research [26]. Based on the Bias\% shown in Table 2, all the 49 completely hemolyzed blood samples (HB: $136.18 \pm 44.28 \mathrm{~g} / \mathrm{L}$ ) were diluted automatically on a Roche Cobas e411 with a ninefold volume of Diluent Universal (Roche Diagnostic GmbH, Mannheim Germany) to keep the final hemoglobin concentration less than $20 \mathrm{~g} / \mathrm{L}$ (HB: $13.62 \pm 4.43 \mathrm{~g} / \mathrm{L}$ ). Then, the concentrations of total $\operatorname{IgE}$ in the serum and diluted completely hemolyzed blood were tested. After obtaining the final test concentration of the completely hemolyzed blood by multiplying the total IgE concentration in the diluted blood by 10 , the results showed that the final test concentration of total $\operatorname{IgE}$ in the completely hemolyzed blood (range: $1.65-532.00 \mathrm{IU} / \mathrm{mL}$, median: $20.24 \mathrm{IU} / \mathrm{mL}$ ) was still significantly lower than that in the serum (range: $3.53-955.70 \mathrm{IU} / \mathrm{mL}$, median: $41.04 \mathrm{IU} /$ $\mathrm{mL})(P<0.05)$, which indicate that only dilution of the completely hemolyzed blood cannot be used to estimate serum IgE levels.

A linear regression analysis was subsequently carried out for all the 49 cases. The results revealed that the test concentrations of total IgE in the completely hemolyzed blood $(x)$ exhibited a strong correlation with those in the corresponding serum $(y)$, and the regression formula was $y=1.7099 x+15.69(r=0.983)($ Fig. 4). Then, we used the regression formula to correct the test concentration of total IgE in the completely hemolyzed blood and obtained the corrected concentration (range: 19.44-924.48 IU/mL, median: $51.16 \mathrm{IU} / \mathrm{mL}$ ), which showed no significant difference with the concentration of total $\operatorname{IgE}$ in serum $(P=0.435)$ (Fig. 5). These observations preliminarily confirmed the feasibility of using the corrected concentrations obtained by the dilution-correction method to estimate serum IgE levels.

\section{Diagnostic ability of the test and corrected concentration of completely hemolyzed blood}

To further verify the effectiveness of the corrected concentration, the forensic diagnostic abilities of total $\operatorname{IgE}$ in the serum, completely hemolyzed blood, and the corrected concentration were compared. According to Lara Tran's study, which regarded a postmortem level of $60 \mathrm{IU} / \mathrm{mL}$ as the cutoff value of serum total IgE, 20 of 49 cases showed a risk for atopic disposition or sensitivity to an allergen [10]. As a result, positive and negative serum total $\mathrm{IgE}$ was observed

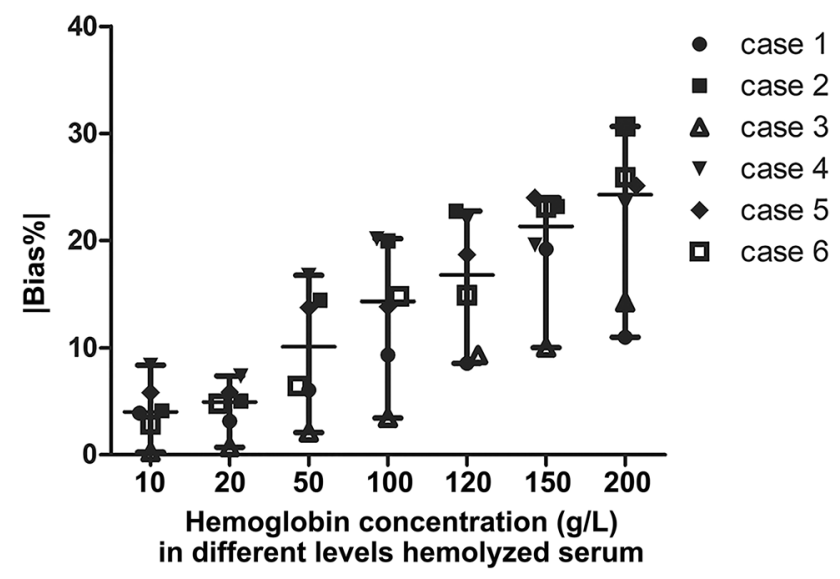

Fig. $3|\mathrm{Bias} \%|$ of total IgE in different levels of hemolyzed serum tested by ECLIA ( $n=6$ in each group) 
in 20 and 29 cases, respectively. Eight false-negative cases (concentration of total $\mathrm{IgE}>60 \mathrm{IU} / \mathrm{ml}$ in the serum but $<60 \mathrm{IU} / \mathrm{ml}$ in the completely hemolyzed blood) occurred with the direct use of the test concentration of total $\operatorname{IgE}$ in the completely hemolyzed blood. However, the corrected concentration of total IgE showed the same diagnosis result as that of serum, indicating that the corrected concentration obtained by the dilution-correction method had the same forensic diagnostic ability as serum.

\section{Discussion}

In the clinical laboratory, hemolysis interferes with the measurement of multiple biomarkers [12-15] for the following main reasons. First, the released intracellular substances from blood cells impact the progress of the assay. In severely hemolyzed postmortem samples, the main intracellular substance is hemoglobin, which has a strong absorbance peak in the spectrum, and a high concentration of hemoglobin also interferes with the binding of antigens and antibodies [27]. Second, in severe hemolysis, the intracellular substances released from blood cells may affect the concentration of serum biomarkers, such as increased serum potassium and decreased serum sodium after hemolysis [13, $28,29]$. In forensic practice, hemolysis of blood samples is more serious due to the effects of postmortem changes. Clinical research indicates that the ECLIA technique uses streptavidin-coated microparticles that are mechanically separated from the supernatant and the potentially interfering substances, so most of the interferences are eliminated in the final buffer [21]. Thus, the ECLIA technique is robust against hemolysis, and the present study applied ECLIA to analyze total IgE in postmortem hemolyzed blood. Our results indicate that hemolysis negatively interfered with the analysis of total IgE by ECLIA. As the level of hemolysis increased, the $|\mathrm{Bias} \%|$ of total $\mathrm{IgE}$ in the hemolyzed blood also increased. Generally, the normal hemoglobin concentration in human blood is $130-160 \mathrm{~g} / \mathrm{L}$ for males and $120-150 \mathrm{~g} / \mathrm{L}$ for females [30]; thus, the total IgE in completely hemolyzed blood samples of a normal human will be decreased by approximate $20 \%$ when analyzed through ECLIA due to interference, according to our results.

A series of evaluation methods and indicators reflect the interference on different biomarkers and test methods in the clinical laboratories, such as the hemolytic index $(\mathrm{HI}), \pm 10 \%$ change of concentrations from baseline $( \pm 10 \% \Delta)[14,31$, 32]. However, for postmortem biochemical analyses, more serious interfering factors are observed relative to clinical situations. Therefore, a set of evaluation methods and indicators should be proposed for different methods and bodily fluid samples used in postmortem biochemical analyses according to the various interfering factors. The present 


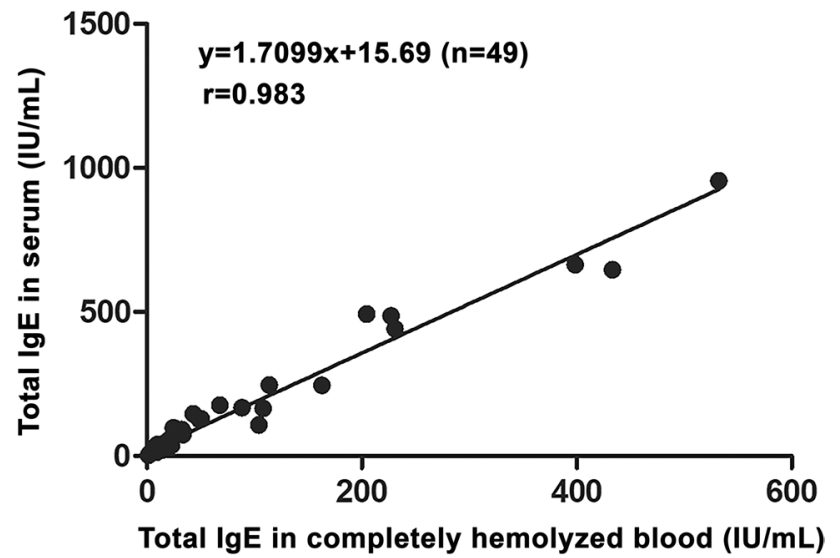

Fig. 4 Linear regression analysis of total IgE concentrations in the completely hemolyzed blood and the corresponding serum $(n=49)$

study used Bias\% as an indicator to evaluate the interference of hemolysis. After a tenfold dilution of the completely hemolyzed blood to a final hemoglobin concentration less than $20 \mathrm{~g} / \mathrm{L}$, |Bias\%| was controlled to less than $10 \%$. The test concentration of total IgE in the completely hemolyzed blood was still approximately twofold lower than that in the corresponding serum $(P<0.05)$. In addition, eight falsenegative values appeared in the completely hemolyzed blood. Regarding the results of the present study and the interference of hemolysis, we speculate that the release of intracellular substances from blood cells may contribute to the dilution of total IgE in the serum, which is similar to the decrease of sodium in postmortem samples [28]. Therefore, the results can be considered positive if the test concentration of total IgE in the completely hemolyzed blood obtained

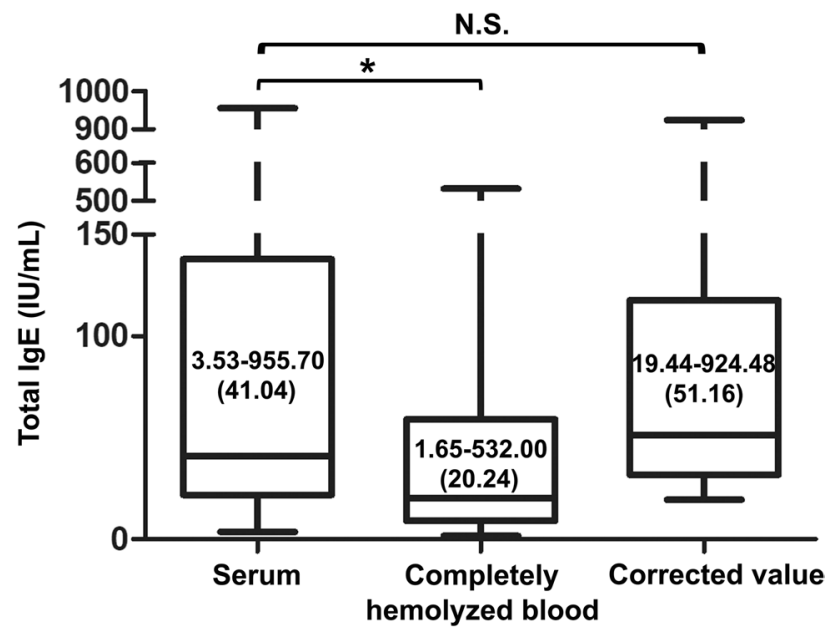

Fig. 5 Concentration of total IgE in the serum and completely hemolyzed blood, and the corrected concentration $(n=49$ in each group). Data in the boxes are presented in a range (median). *There was a statistically significant difference between the test concentration of total IgE in completely hemolyzed blood and that in serum (Wilcoxon signed-rank paired test, $P<0.05$ ). N.S., no significance through ECLIA is higher than the cutoff value. However, false-negative values cannot be excluded if the test concentration in the completely hemolyzed blood is lower than the cutoff value. Consequently, the test concentration of total $\mathrm{IgE}$ in completely hemolyzed blood is not recommended for direct use in forensic diagnostics.

The concentration of total IgE corrected by the regression formula showed no significant difference with the total IgE in serum $(P>0.05)$ and exhibited the same diagnostic ability as serum. Therefore, we believe that the corrected concentration can be used to evaluate the concentration of total IgE in serum for diagnostics when hemolysis is severe and serum is not available.

Certain limitations were observed in the present study. First, the number of included cases was relatively small. More samples will lead to a better regression analysis, and the corrected concentration will be more accurate. However, we believe that the method in the present study for the evaluation of serum total IgE concentrations from completely hemolyzed blood samples of these 49 cases is effective. Second, as we discussed above, in addition to the influence of hemoglobin and other interfering substances, the dilution of serum caused by the release of intracellular substances also leads to hemolysis-induced interference on the analysis of total $\operatorname{IgE}[13,27,29]$. We believe that hematocrit (HCT), an indicator that reflects the proportion of red blood cells in the volume of whole blood, may act as another useful correction factor [33, 34]. Regrettably, because of the equipment limitations in our laboratory, the influence of HCT was not investigated in the present study. Therefore, the regression formula should be established according to the different situations in each laboratory.

In conclusion, the present study demonstrated that hemolysis negatively interferes with the biochemical analysis of total IgE by ECLIA and that more severe hemolysis corresponds to greater interference. Therefore, completely hemolyzed blood is not recommended for direct postmortem analysis of total $\mathrm{IgE}$, and the corrected concentrations obtained by the dilution-correction method might be of potential utility in forensic practice for evaluating serum total IgE concentrations. Although further studies may be needed, this pilot study provides a possible method for total IgE analysis in postmortem hemolyzed blood.

Author contribution The study was designed by Baoli Zhu and Zhipeng Cao. The acquisition and analysis of data and interpretation of the results were carried out by Tianqi Wang, Zeyu Li, and Yuqing Jia. The manuscript was written by the corresponding author, who critically revised it for important intellectual content based on a previous version written by Tianqi Wang and Zeyu Li.

Funding This study was funded by the National Natural Science Foundation of China (grant nos. 81273343 and 82002001) and the Natural Science Foundation of Liaoning Province (grant no. 20180530004). 


\section{Declarations}

Ethics approval This study was approved by the Ethics Committee of China Medical University and was performed in accordance with the 1964 Declaration of Helsinki. All biological samples were anonymized prior to analysis and analyzed in the same laboratory. No ethical approval was necessary to perform biochemical analyses in the collected cases.

Competing interests The authors declare no competing interests.

\section{References}

1. Ansari MQ, Zamora JL, Lipscomb MF (1993) Postmortem diagnosis of acute anaphylaxis by serum tryptase analysis. A case report. Am J ClinPathol 99(1):101-103. https://doi.org/10.1093/ajcp/99.1.101

2. Pumphrey RS, Roberts IS (2000) Postmortem findings after fatal anaphylactic reactions. J Clin Pathol 53(4):273-276. https://doi. org/10.1136/jcp.53.4.273

3. McLean-Tooke A, Goulding M, Bundell C, White J, Hollingsworth P (2014) Postmortem serum tryptase levels in anaphylactic and non-anaphylactic deaths. J Clin Pathol 67(2):134-138. https://doi.org/10.1136/jclinpath-2013-201769

4. Maeda H, Ishikawa T, Michiue T (2011) Forensic biochemistry for functional investigation of death: concept and practical application. Leg Med (Tokyo) 13(2):55-67. https://doi.org/10. 1016/j.legalmed.2010.12.005

5. Nishio H, Takai S, Miyazaki M, Horiuchi H, Osawa M, Uemura K, Yoshida K, Mukaida M, Ueno Y, Suzuki K (2005) Usefulness of serum mast cell-specific chymase levels for postmortem diagnosis of anaphylaxis. Int J Legal Med 119(6):331-334. https://doi.org/10.1007/s00414-005-0524-1

6. Sun KJ, He JT, Huang HY, Xue Y, Xie XL, Wang Q (2018) Diagnostic role of serum tryptase in anaphylactic deaths in forensic medicine: a systematic review and meta-analysis. Forensic Sci Med Pathol 14(2):209-215. https://doi.org/10. 1007/s12024-018-9980-z

7. Tse R, Wong CX, Kesha K, Garland J, Tran Y, Anne S, Elstub H, Cala AD, Palmiere C, Patchett KL (2018) Post mortem tryptase cut-off level for anaphylactic death. Forensic Sci Int 284:5-8. https://doi.org/10.1016/j.forsciint.2017.12.035

8. Yunginger JW, Nelson DR, Squillace DL, Jones RT, Holley KE, Hyma BA, Biedrzycki L, Sweeney KG, Sturner WQ, Schwartz LB (1991) Laboratory investigation of deaths due to anaphylaxis. J Forensic Sci 36(3):857-865

9. Horn KD, Halsey JF, Zumwalt RE (2004) Utilization of serum tryptase and immunoglobulin e assay in the postmortem diagnosis of anaphylaxis. Am J Forensic Med Pathol 25(1):37-43. https://doi.org/10.1097/01.paf.0000113814.56572.de

10. Tran L, Astengo B, Palmiere C (2016) Determination of specific $\mathrm{IgE}$ in pericardial and cerebrospinal fluids in forensic casework. Forensic Sci Int 267:204-209. https://doi.org/10.1016/j.forsc iint.2016.08.021

11. Khan BQ, Kemp SF (2011) Pathophysiology of anaphylaxis. Curr Opin Allergy Clin Immunol 11(4):319-325. https://doi. org/10.1097/ACI.0b013e3283481ab6

12. Lippi G, Salvagno GL, Montagnana M, Brocco G, Guidi GC (2006) Influence of hemolysis on routine clinical chemistry testing. Clin Chem Lab Med 44(3):311-316. https://doi.org/ 10.1515/CCLM.2006.054

13. Koseoglu M, Hur A, Atay A, Cuhadar S (2011) Effects of hemolysis interferences on routine biochemistry parameters.
Biochem Med (Zagreb) 21(1):79-85. https://doi.org/10.11613/ bm.2011.015

14. Agarwal S, Vargas G, Nordstrom C, Tam E, Buffone GJ, Devaraj S (2015) Effect of interference from hemolysis, icterus and lipemia on routine pediatric clinical chemistry assays. Clin Chim Acta 438:241-245. https://doi.org/10.1016/j.cca.2014.08.008

15. Yanagisawa Y, Isobe K, Naito A, Ishijima M, Nanmoku T, Yamamoto T, Suzuki E, Kawakami Y (2017) Influence of in vitro hemolysis on 80 different laboratory tests. Clin Lab 63(2):219 226. https://doi.org/10.7754/Clin.Lab.2016.160305

16. Cao Z, Jia Y, Zhu B (2019) BNP and NT-proBNP as diagnostic biomarkers for cardiac dysfunction in both clinical and forensic medicine. Int J Mol Sci 20(8):1820. https://doi.org/10.3390/ijms2 0081820

17. Kulasingam V, Jung BP, Blasutig IM, Baradaran S, Chan MK, Aytekin M, Colantonio DA, Adeli K (2010) Pediatric reference intervals for 28 chemistries and immunoassays on the Roche cobas 6000 analyzer-a CALIPER pilot study. Clin Biochem 43(1314):1045-1050. https://doi.org/10.1016/j.clinbiochem.2010.05. 008

18. Borta SM, Dumitra S, Miklos I, Popetiu R, Pilat L, Puschita M, Marian C (2020) Clinical relevance of plasma concentrations of MBL in accordance with IgE levels in children diagnosed with bronchial asthma. Medicina (Kaunas) 56(11):594. https://doi.org/ 10.3390/medicina56110594

19. Meany D, Schowinsky J, Clarke W (2008) Effects of hemolysis and lipemia on the COBAS salicylate and acetaminophen assays compared to GDS assays. Clin Biochem 41(18):1486-1488. https://doi.org/10.1016/j.clinbiochem.2008.09.111

20. Syme NR, Toft AD, Stoddart M, Beckett GJ (2011) Clinical performance of the Roche cobas e411 automated assay system for thyrotropin-receptor antibodies for the diagnosis of Graves' disease. Ann Clin Biochem 48(Pt 5):471-473. https://doi.org/10. 1258/acb.2011.011013

21. Lippi G, Mercadanti M, Romero A, Lipreri G, Salvagno GL, Guidi GC (2012) Spurious hemolysis does not influence the reliability of digoxin testing on Siemens RXL MAX and Roche Cobas e601. Ann Clin Lab Sci 42(3):302-306

22. Teimouri A, Modarressi MH, Shojaee S, Mohebali M, Zouei N, Rezaian M, Keshavarz H (2018) Detection of toxoplasma-specific immunoglobulin $\mathrm{G}$ in human sera: performance comparison of in house Dot-ELISA with ECLIA and ELISA. Eur J Clin Microbiol Infect Dis 37(8):1421-1429. https://doi.org/10.1007/ s10096-018-3266-y

23. Tang NY, Yeo KJ, van Wijk XMR (2020) Evaluation of interference effects from hemolysis, icterus and lipemia on the Roche Elecsys(R) Anti-SARS-CoV-2 assay. Clin Chim Acta 509:293294. https://doi.org/10.1016/j.cca.2020.06.041

24. Jia Y, Wang T, Tian M, Xue J, Xiao Y, Cao Z, Zhu B (2019) Experimental study on the interference of hemolytic pericardial fluid on the detection of NT-proBNP. Chin J Forensic Med 34(04):349-353. https://doi.org/10.13618/j.issn.1001-5728.2019. 04.006

25. Jia Y, Tian M, Wang T, Wu S, Zhu B, Cao Z (2020) The estimation of postmortem serum urea via the ultrafiltration of hemolyzed blood. J Forensic Sci 65(5):1761-1766. https://doi.org/10.1111/ 1556-4029.14474

26. Zhang S, Wang W, Zhao H, Zhang C, Zhong K, He F, Yuan S, Wang Z (2016) Preliminary study on allowable total error and allowable imprecision in tests for specific proteins in China. Chin J Clin Lab Sci 34(07):602-607. https://doi.org/10.13602/j.cnki. jcls.2016.07.18

27. Tate J, Ward G (2004) Interferences in immunoassay. Clin Biochem Rev 25(2):105-120

28. Singh D, Prashad R, Parkash C, Bansal YS, Sharma SK, Pandey AN (2002) Linearization of the relationship between serum 
sodium, potassium concentration, their ratio and time since death in Chandigarh zone of North-West India. Forensic SciInt 130(1):1-7. https://doi.org/10.1016/s0379-0738(02)00267-0

29. Dimeski G (2008) Interference testing. Clin Biochem Rev 29(Suppl 1):S43-48

30. Hoff CM (2012) Importance of hemoglobin concentration and its modification for the outcome of head and neck cancer patients treated with radiotherapy. Acta Oncol 51(4):419-432. https://doi. org/10.3109/0284186X.2011.653438

31. Nikolac Gabaj N, Miler M, Vrtaric A, Hemar M, Filipi P, Kocijancic M, Supak Smolcic V, Celap I, Simundic AM (2018) Precision, accuracy, cross reactivity and comparability of serum indices measurement on Abbott Architect c8000, Beckman Coulter AU5800 and Roche Cobas 6000 c501 clinical chemistry analyzers. Clin Chem Lab Med 56(5):776-788. https://doi.org/10.1515/ cclm-2017-0889
32. Monneret D, Mestari F, Atlan G, Corlouer C, Ramani Z, Jaffre J, Dever S, Fressart V, Alkouri R, Lamari F, Devilliers C, ImbertBismut F, Bonnefont-Rousselot D (2015) Hemolysis indexes for biochemical tests and immunoassays on Roche analyzers: determination of allowable interference limits according to different calculation methods. Scand J Clin Lab Invest 75(2):162-169. https://doi.org/10.3109/00365513.2014.993691

33. Mondal H, Budh DP (2020) Hematocrit. In: StatPearls. Treasure Island (FL),

34. Nguyen WB, Wyse JM, Drollinger SM, Cheng K (2020) Anemia screening in naval aviation: is hemoglobin a better indicator than hematocrit as the primary index? Mil Med 185(3-4):461-467. https://doi.org/10.1093/milmed/usz243

Publisher's Note Springer Nature remains neutral with regard to jurisdictional claims in published maps and institutional affiliations. 